Deciding Whether to Offer "Early-Bird” or "Night-Owl” Specials in Restaurants:

\title{
A Cross-Functional View
}

Gary M. Thompson

Cornell University 


\begin{abstract}
In a long history of capacity and demand management research in services, it has often been suggested that pricing discounts and specials can increase demand in off-peak periods. We examine this issue in the contexts of restaurants, where the practices of offering discounts to restaurant patrons for dining early or dining late—commonly known as “early-bird” and “night-owl” specials, respectively_ exist throughout the world. These specials bridge marketing and operations-marketing from the goal of increasing customer demand in the off-peak periods and operations from the perspective of having to serve those customers. The effectiveness of these specials has yet to be examined. While simulation would be an ideal tool for predicting the specials’ net revenue benefits, it might be impractical for many restaurateurs, so we develop three simple “back-of-the-envelope” type calculations. Restaurateurs could use these calculations when deciding whether to offer a special. In the eight large simulation-based experiments we conducted, we find that it is important to estimate revenue cannibalization from full-fare customers. The calculations prove to be far more accurate for night-owl specials than for early-bird specials. This has important implications for decisions about offering the specials and raises a flag regarding a potential marketing-operations conflict.
\end{abstract}

\title{
Keywords
}

revenue management, service pricing, demand and capacity management, restaurants, simulation 


\section{Introduction}

Balancing capacity with demand is a classic issue in services. Because service cannot be inventoried, capacity must be available at the time customers are present. Typically, there are reasons that demand materializes at certain times. For example, demand for tax preparation services materializes prior to tax filing deadlines. A goal of marketing-increasing the number and revenue from the customers served — can exacerbate the operational challenges of serving customers, if they all want service at the same time.

Our focus in this article is on a particular example of a demand-capacity balancing context, specifically early-bird and night-owl specials in restaurants. These are specials offered to customers for dining at pre-peak and post-peak times, respectively. Because they bridge marketing and operations, they are interesting from a research perspective. Moreover, restaurants in a number of countries offer earlybird specials. With restaurant sales in the United States alone forecast to be over US\$455 billion in 2014 (Anonymous, 2014), such specials offer restaurateurs a perhaps enticing potential for increasing revenue.

If capacity could be added inexpensively, one would never need to worry about peak demand. However, in many instances, capacity cannot be added inexpensively. In a restaurant context, while staff are relatively low cost and generally easy to acquire, capacity is largely determined by the size of the restaurant, that is, the front of house - where customers eat — and the back of house — where meals are prepared. The cost of increasing this capacity is significant. So, good restaurants - those where service, food, ambience, and prices all meet or exceed customers' expectations—are popular and that popularly leads to demand exceeding capacity at peak times (e.g., Friday and Saturday evenings).

If, again, the goal of marketing is to increase business, attempting to drive more business at peak times will not be effective if capacity is maxed out. Certainly, prices could be increased at peak times, with the aim of balancing demand with supply (i.e., capacity). However, research has shown that restaurant customers are not receptive to premium pricing in peak periods, though they are receptive to 
discounted prices at nonpeak times (Wirtz and Kimes 2007). The specials we examine offer the potential of increasing revenue without adding to peak capacity and so could be quite appealing from a marketing perspective.

The rationale for offering early-bird (night-owl) specials is to increase demand in the pre-peak (post-peak) period, with the hope that the increase in demand yields a net revenue benefit. Clearly, however, increasing overall demand can have implications for operations because the peak and nonpeak times are not independent of each other. Customers using early-bird specials can cannibalize the capacity available in the peak period, while the capacity available to serve night-owl customers can be cannibalized by customers who arrived earlier, during the peak period. Capacity cannibalization can result in the specials yielding lower revenue benefits than expected. Though early-bird specials have been examined from the perspective of customers (Susskind, Reynolds, and Tsuchiya 2004), we are, to our knowledge, the first to examine their effect on operations. To our knowledge, night-owl specials have not been examined before.

Our aim is to help managers make good decisions regarding whether or not to implement either type of special. Specifically, we look for a simple yet accurate way of estimating the net value of offering a special. Knowing the extent of the discount being offered, and the increase in off-peak demand to be expected, the net benefit of the specials can be estimated using simple, back-of-the-envelope type calculations that can be easily performed in a spreadsheet. Using eight large computer simulation experiments, we evaluate three back-of-the envelope calculations, one of which incorporates cannibalization effects. While there are some restaurant operations contexts where back-of-the-envelope approaches work quite well, there are others where simple calculations are quite inaccurate. We find that our estimate that considers cannibalization — the best of the three- has mixed results, working well for night-owl specials but notably less well for early-bird specials. These mixed results highlight the potential conflict that can arise from a well-intentioned marketing idea that fails to deliver the promised benefits. 
The next section reviews relevant literature, followed by the three back-of-the-envelope calculations that we investigate for evaluating the net benefit of the specials. The simulation studies come after that, where we present the experimental factors, and then our results. We close with a discussion and some brief conclusions. An Online Appendix presents examples of early-bird specials from restaurants around the world. In that appendix, we also list and provide rationale for the assumptions of the simulation studies and show a numerical example for the best-performing back-of-the-envelope estimate of the value of a special.

\section{Literature Review}

There is nearly a four-decade history of demand-capacity management research in services. Sasser (1976) provided two capacity strategies: Matching capacity to demand and maintaining a level capacity. He also suggested that demand can be affected by off-peak pricing and nonpeak promotions, both of which encapsulate early-bird and night-owl specials. He noted, though “... caution must be used in developing plans to increase demand for underused periods of the service facility. Many companies have made costly mistakes by introducing such schemes and not seeing the impact they would have expected on operations’' (p. 137). Our results show that he was prescient with respect to early-bird specials.

Lovelock (1984) presented five methods of managing demand and considered each under the three situations where capacity was insufficient, sufficient, and excess. The five methods were taking no action, reducing demand through higher prices, increasing demand by pricing lower and marketing efforts, inventorying demand through reservations systems, and inventorying demand through queuing systems. In the context we examine—-walk-in restaurants—reservations are not applicable. While higher prices could be applied in peak periods, restaurant customers view discounts more favorably than premiums (Wirtz and Kimes 2007), so we base our investigation on lower prices. 
Rhyne (1988) offered demand management ideas that complement and supplement Lovelock’s five methods. His new suggestions were that demand could be altered by rationing and managing nonpeak periods. Managing nonpeak periods is the issue we examine in this article, through the use of the earlybird and night-owl specials.

Kimes (1989) described how yield management could be applied in service firms with limited capacity. Variable pricing had been identified earlier, but Kimes introduced the idea of controlling how the inventory (i.e., capacity) is made available to customers. In a walk-in restaurant context, this is like deciding what mix of tables would be used, which affects the mix of parties that can be served. As part of our investigation, we ensure that the mix of capacity we use is the best possible.

Crandall and Markland (1996) presented a survey of demand management-actions across six service industries. Their "influence”' strategy, which meant the organization attempted to change demand patterns - the context we investigate - was the third most used strategy, on average, across the industries. It fell below providing sufficient capacity and matching capacity to demand, but above controlling demand variation. These results are intuitively appealing, since they show that organizations first try to meet, before attempting to move, demand.

Klassen and Rohleder (2001) categorized demand management options into shorter term and longer term, with price differentials falling in the shorter term category. Another shorter term option they identified was service differentials. While we assume that the service offering for the early-bird and nightowl specials is the same as for regular diners, we return to the potential importance of this option in the discussion.

Klassen and Rohleder (2002) presented a general mathematical programming model of the capacity-demand management problem and used it to explore when different options would be used. They found that the best strategies were context sensitive. In the environment like the one we consider, where capacity is largely fixed, they found the price differential strategy and the inform/educate strategy to be 
most effective. Their findings lead us to expect that early-bird and night-owl specials would be beneficial, with appropriately informed customers.

Recently, Dixon et al. (2014) presented a summary of conceptual and empirical papers that “support the notion”' (p. 288) that congruence of marketing and operations leads to better organizational performance. Our investigation uses a specific context to examine a potential disconnect between marketing and operations. The literature contains few other context-specific examples of the marketingoperations, demand-capacity interaction, including the following: pizza delivery (Verma, Thompson, and Louviere 1999), movie rentals (Evangelist et al. 2002), and a ski resort (Pullman and Thompson 2003). Kwortnik and Thompson (2009) used a case study of a cruise line and described the inherent operational challenges posed by the firm's marketing efforts. They used these problems as the basis for developing a model for integrated service management. They note that " only by having an integrated approach to service design, marketing, and delivery can organizations hope to avoid service-system challenges ... "’ (p. 402). Early-bird and night-owl specials are just such issues, since they are marketing approaches to increasing revenue, but have clear implications for operations because the customers using the special need to be served, with, ideally, minimal effect on the full-fare customers. The specials also fall in the “measuring and optimizing the value of service” topic, 1 of the 10 service-related topics for which a recent article in this journal called for research (Ostrom et al. 2010) and within the "customer segmentation'” topic, 1 of the 7 topics on managing customers for value for which Kumar, Lemon, and Parasuraman (2006) suggested additional research.

The literature on restaurant revenue management (RRM) is of some relevance to our studies. Since Kimes et al. (1998) first coined the term “'restaurant revenue management”' (RRM), the term has come to mean the actions—-both marketing and operational—-that restaurateurs take to drive revenue. Thompson (2010) presented a summary of RRM-related research that had appeared in the Cornell Hospitality Quarterly and listed areas in need of future research. Price discounting was one of the listed topics. Clearly, early-bird and night-owl specials fall in this realm. Quain, Sansbury, and LeBruto (1999) 
advocated encouraging more business at off-peak times. Wirtz and Kimes (2007), who used restaurants as one of their study contexts, used different pricing by time periods, a concept they stated was common practice in Singapore, where they collected their data. Susskind, Reynolds, and Tsuchiya (2004) observed that "many restaurant patrons would accept discounts as an incentive for changing their dining time to off-peak hours... “ (p. 78). Lefever (1989) gave an interesting narrative about his restaurant’s negative experience with early-bird specials, namely, issues with customers who expected to be able to receive the special outside the specified time.

The efficacy of back-of-the-envelope type calculations for restaurant operations has been addressed on several occasions. Such calculations have found to perform well for table mixes (Kimes and Thompson 2005; Thompson 2011b) but not well for the revenue benefits from reducing dining duration (Thompson 2009). We believe that back-of-the-envelope calculations for early-bird and night-owl specials will be inaccurate, like those for the benefit of reducing dining duration, unless cannibalization effects are considered. Our rationale for this belief is that the time periods in which the specials are offered — the pre-peak and post-peak periods—are not independent of the peak period, because diners arriving for an early-bird special can spill over into the peak period, and thus cannibalize capacity better dedicated to full-fare customers; while in the case of night-owl specials, full-fare customers could spill over from the peak period into the night-owl period, leaving less capacity than expected to serve the customers wanting the special. Cannibalized capacity typically would lead to lower-than-expected net revenue accruing from the specials. We explore these ideas by evaluating the effectiveness of three backof-the-envelope calculations, which we introduce in the next section.

\section{Back-of-the-Envelope Approaches to Calculating the Net Value of the Specials}

To decide whether to implement an early-bird or night-owl special, presumably a manager would want to estimate the special's net value to the restaurant. While using a complex simulation model would 
be ideal, along the lines of that of Evangelist et al. (2002), this could be impractical for many restaurateurs. Subsequently, we present three methods for estimating the net value (i.e., revenue or contribution) accruing from the specials. While the estimates range from very simple to moderately complex, they all could be easily done spreadsheet and as such do not require access to any complex tools.

Before showing the calculations, we define terms. First, we assume the meal period is broken into periods (intervals) of the same duration (e.g., 15 minutes). Within the entire meal period, there is a set of periods where demand is at its peak; these peak periods are surrounded by shoulder periods. It is in the shoulder periods where the specials are targeted. So:

$$
\begin{aligned}
& i=\text { index for planning intervals (periods); } \\
& I=\text { the set of planning intervals (periods); } \\
& P=\text { the set of planning intervals experiencing peak demand; and } \\
& d=\text { the mean meal duration, in intervals. }
\end{aligned}
$$

We have several parameters defined on a period-specific basis:

$$
\begin{aligned}
& \operatorname{oepar}_{i}=\text { original expected party arrival rate in period } i \text { (i.e., parties per period); }_{\text {separ }_{i}=\text { special-affected expected party arrival rate in period } i \text { (parties per period); and }} \\
& \operatorname{ppwd}_{i}=\text { proportion of parties arriving in period } i \text { who want the special. }
\end{aligned}
$$

There are six parameters that are common across the meal period:

$$
\begin{aligned}
& \text { ppar }=\text { peak party arrival rate (in parties per period); } \\
& \text { msar = maximum serviceable party arrival rate per period (i.e., capacity), in parties; } \\
& \text { value = weighted average value of a party; }
\end{aligned}
$$


otev $=$ original total expected value across all parties;

spcprop $=$ special proportion (i.e., the value of a party using the special, as a proportion of the value of a full-fare party);

$c a f_{e b}=$ cannibalization adjustment factor for the early-bird specials; and

$c a f_{n o}=$ cannibalization adjustment factor for the night-owl specials.

Of the needed parameters, most are available from the historical record of the restaurant, in the point of sale system data. However, it is important to note that a manager would need to estimate the party arrival rate when the special was in place (the $\operatorname{separ}_{i}$ values) and the proportion of parties desiring the special (the $p p w d_{i}$ values). We return to this in the discussion.

Both the special proportion and cannibalization adjustment factors listed previously need further explanation. The special proportion represents the value of a customer using the special, as a proportion of a full-fare customer's value. Because of the way it is defined, the special proportion could be considered to a discounted sales price proportion if the value is being calculated as revenue or it could be a discounted contribution proportion if the value is being measured as contribution. We note that the particular nature of the special will affect the numerical value of this parameter.

The cannibalization adjustment factor represents a multiplier of the estimated cannibalization of full-fare business. By using a cannibalization adjustment factor in the calculations shown subsequently, we can better approximate the capacity (and revenue) cannibalization that occurs in a dynamic restaurant setting. The value of this parameter is very important, and much of our effort in the article is on establishing a good rule-of-thumb value for the cannibalization adjustment factor, to ensure that the backof-the-envelope calculations work as well as they possibly can.

Finally, we have the three estimations of the value accruing from the specials:

ValEst 1 = net special-affected total expected value across all parties, Method 1; 
ValEst2 $=$ net special-affected total expected value across all parties, Method 2; and

ValEst3 $=$ net special-affected total expected value across all parties, Method 3.

Subsequently, we show how the value estimates are calculated. We begin by calculating an original estimate of the total value the restaurant achieves during the meal period:

$$
\text { otev }=\text { value } \times \sum_{i \in I}\left(\min \left(\text { oepar }_{i}, \text { msar }\right)\right)
$$

The estimated revenue before the special is implemented (Equation 1) is calculated by multiplying the value of a party times the sum, across all periods, of the lower of the period's party arrival rate and the restaurant's capacity. This value should match the restaurant's historical records from the point-of-sale system.

The first estimate of the value of the special, sums, for all periods, the special-influenced party arrival rate in the period, times the average party value for the period and then subtracts the original value:

$$
\text { ValEst } 1=\sum_{i \in I}\left(\operatorname{separ}_{i} \times\left(\left(1-\text { ppwd }_{i}\right) \times \text { value }+p p w d_{i} \times \text { value } \times \text { spcprop }\right)\right)-\text { otev }
$$

Note that the party value for a period is given by the proportion of parties in the period that do not select the special, times the value they each provide, plus the proportion that select the special, times the value they each provide.

The second estimate of the value of the special is very similar to the first, except that it limits the number of customers served in each period to the capacity: 


$$
\begin{aligned}
\text { ValEst } 2=\sum_{i \in I} & \left(\min \left(\text { separ }_{i}, \text { msar }\right) \times\left(\left(1-\text { ppwd }_{i}\right) \times \text { value }+p p w d_{i} \times \text { value } \times \text { spcprop }\right)\right) \\
& - \text { otev. }
\end{aligned}
$$

Because of the capacity limit imposed in Equation 3, ValEst $_{2}$ will be a more conservative estimate of the value of the special than will ValEst . $_{\text {. }}$

ValEst $_{3}$ is even more conservative than the second and it comes in two forms —one for earlybird specials, Equations 4 and 5, and one for night-owl specials, Equations 6 and 7. Both forms start from ValEst2 and then subtract an estimate of the cannibalization of full-fare business (i.e., capacity) that will result from the special. For the early-bird specials, we first estimate the cannibalization that will occur:

$$
\text { cnblest }_{e b}=\text { value } \times \sum_{i \in P}\left(\max \left(\operatorname{separ}_{i}+\left(\operatorname{separ}_{i-d}-\text { oepar }_{i-d}\right)-\text { msar }_{, 0}\right)\right)
$$

Equation 4 assumes that the number of full-fare parties that are cannibalized in period $i$ is the amount by which the additional parties coming in from the special, who arrived $d$ periods earlier, added to the customers arriving in the full-fare period, exceed the available capacity. (We also tested a version of Equation 4 that considers that parties taking the special can affect capacity in up to d periods, but it did not work as well as the version we present.) We then subtract, from the second value estimate, a multiple — the cannibalization adjustment factor — of the estimated cannibalization, to arrive atValEst $3_{e b}$ :

$$
\text { ValEst }_{e b}=\text { ValEst } 2-c a f_{e b} \times \text { cnblest }_{e b} .
$$

Similarly, the third estimate for the night-owl special begins with an estimate of the capacity that could be devoted to the night-owl customers but is in fact used by full-fare customers who arrived earlier:

$$
\text { cnblest }_{n o}=\text { value } \sum_{i \in I}\left(\max \left(\operatorname{separ}_{i}+\left(\operatorname{separ}_{i+d}\right)-\text { msar } 0\right)\right)
$$


Note that Equation 6 uses a cannibalization factor from $d$ periods into the future. At first, it may seem counterintuitive that later-arriving customers can affect sales in the current period. However, the equation is designed to capture the fact that parties who arrived during the peak interval, who might still be waiting for service in the period in which the special applies, could reduce the number of (new) special-desiring customers who would be served. As for the early-bird estimate, we then subtract a multiple (the cannibalization adjustment factor) of the estimated cannibalization from the second value estimate, to arrive atValEst $2_{n o}$ :

$$
\text { ValEst } 2_{n o}=\text { ValEst2 }- \text { caf }_{\text {no }} \times \text { cnblest }_{n o} .
$$

Both Equations 5 and 7 use the cannibalization adjustment factor mentioned previously, though we allow different values for early-bird and night-owl cases. Simply put, the cannibalization adjustment factor is a multiplier of the cannibalization in Equations 4 and 6. It could range from zero to values higher than one. Zero would be where no cannibalization occurs, in which case ValEst2 and ValEst3 would be identical. A cannibalization adjustment factor of 1.0 would be full cannibalization, as we measure it in Equations 4 and 6. Since the estimate of cannibalization in Equations 4 and 6 may, in actuality, fall below the true cannibalization that occurs, a cannibalization adjustment factor higher than one might be appropriate, which we do see in some cases for both specials. Obviously, bigger cannibalization adjustment factor values yield bigger differences between ValEst2 and ValEst3. We also note that the cannibalization estimates in Equations 4 and 6 only apply if demand exceeds capacity, so any cannibalization effect would be small or nonexistent in restaurants where peak demand was below capacity. In our studies, we evaluate a range of values for the cannibalization adjustment factors, which will enable us to provide general advice to managers.

The nature of these calculations leads us to expect that:

1) ValEst1 will be the least accurate estimate of the special value; 
2) ValEst2 will perform better than ValEst1, since it considers that capacity limits the number of customers served; and

3) ValEst3 will be the most accurate, since it offers a means of addressing the cannibalization effects.

Our simulation studies, which we discuss next, were created to test the effectiveness of the three value estimators in early-bird and night-owl settings.

\section{Simulation Studies}

To evaluate the accuracy of the three methods of estimating the net value of the specials, we selected the methodology of discrete-event simulation. There are a number of advantages of using simulation. First, it allows us to evaluate a very large number of different restaurant contexts. Second, we can easily construct full-factorial designs. Third, we are not limited to cases where restaurants

\section{INSERT TABLE 1 HERE}

implemented specials, as data accuracy can be problematic in restaurants (Kimes and Beard, 2013). As we describe subsequently, we created a model that simulates the arrival and service of restaurant patrons. We vary many characteristics in the model, allowing us to examine the issue of specials in a very broad way. This model is akin to those of Evangelist et al. (2002) and Pullman and Thompson (2003), for examining the effects of capacity and demand decisions in services.

We conducted eight simulation-based studies, as summarized in Table 1. All of the studies evaluate the special-value calculations using 15-minute planning periods. The studies differed based on whether they used early-bird or night-owl specials, whether the specials were assumed to simply increase demand in the special window or move demand from the peak period to the special window, or whether the special applies to all diners in the special window or only to the incremental customers. Studies 1-4 
use early-bird specials, while Studies 5-8 use night-owl specials. Studies 1, 2, 5, and 6 assume that the specials increase demand in the special window, without affecting demand at any other time, while Studies 3 and 4 (7 and 8) assume that some customers who would have arrived in the peak demand period, but within an hour of the special, arrive an hour earlier (later) than they would have. In Studies 1, 3, 5, and 7, we assume that all existing customers, plus any incremental customers accruing from the special, use the special pricing. In Studies 2, 4, 6, and 8, we assume that only the incremental customers accruing from the special use the special pricing, while the existing customers continue to purchase as before. Other than these differences, the eight studies share many experimental factors, which we categorize as environment related and special related. A description of the factors follows.

\section{Environmental Factors}

All studies had seven environmental factors defining the characteristics of the restaurants and customers, as presented in Table 2. We selected these factors, and their levels, to give a broad range of

\section{INSERT TABLE 2 HERE}

restaurant environments and because we believed these factors could affect the accuracy of the special benefit calculations. Since we used a full factorial design, the levels of the environmental factors yielded a total of 144 environments.

We selected two sizes of restaurants for the Restaurant Size factor 50 and 200 seats. The larger size we consider falls within the median and mean restaurant sizes of 150 and 211 seats in a survey conducted by Thompson (2011a).

Peak Demand Intensity had three levels, ranging from 90\% to $110 \%$ of full capacity. Earlier studies have ranged from a low of 95\% of full capacity (Thompson and Sohn 2009) to a high of 300\% of full capacity (Thompson 2011b) but most falling around full capacity (Thompson 2002, 100\%; Kimes and 
Thompson 2005, 100\%; Thompson and Sohn 2009, 105\%; Kimes and Thompson 2005, 120\%; Thompson 2011a, 130\%). While a common premise of RRM is that demand exceeds capacity, we include the $90 \%$ level because that might be just the kind of situation in which restaurateurs would be interested in offering the specials.

Length of Peak (demand) Period had two levels, of 2 and 4 hours. This represents the amount of time during which customers arrive at the highest rate. From the length of the peak period, it should be clear that we are simulating a single meal period. With a mean dining duration of 60 minutes, the peak duration means that the restaurant should be able to turn its tables about twice and about four times for the two levels of this factor. Anecdotal evidence suggests that most full service restaurants have fewer than four table turns in a single meal period.

Length of Ramp-Up Period is the time difference between a restaurant's opening for meal service and the time at which the peak customer arrival rate first occurs. We used two levels for this factor in Studies 1-4, representing ramp-up periods of 1 and 2 hours. In Studies 5-8, we held the ramp-up duration at a constant 1 hour. In all studies, we assumed that demand would ramp up linearly.

Length of Ramp-Down Period is the time difference between when the peak customer arrival rate last occurs and the restaurant's closing for meal service. In Studies 5-8, we used two levels for this factor, representing ramp-down periods of 1 and 2 hours. Studies 1-4 used a constant ramp-down period of 1 hour. All studies assumed that demand would ramp down linearly.

Various authors have observed that dining duration increases with party size (Bell and Pliner 2003; Kimes and Robson 2004; Kimes and Thompson 2004). We captured this phenomenon using the Dining Duration Variation by Party Size factor. This factor had two levels, that is, ratios of the mean dining time for a party of 10 compared to the mean dining time for a party of one of 1.5 and 2.0. These ratios fall in the range reported in the literature-a low of 1.14 (Kimes and Thompson 2004) to a high of 3.18 (Bell and Pliner 2003). For both levels, we assumed that dining duration increased linearly across party sizes. With the party size probabilities and dining times we used (reported in Table 3), both factor levels maintained a weighted average dining time of 60 minutes and a mean party size of 2.6 people. To 
the best of our knowledge, mean party size is reported explicitly for individual restaurants only by Kimes and Robson (2004) and Thompson (2011b); in their cases, it was 2.6 and 2.55 people per party, respectively.

The last environmental factor is Wait Tolerance by Party Size, which had three levels. Anecdotal evidence suggests that larger parties are willing to wait longer for a table than are smaller parties (Field, McKnew, Kiessler 1997), although we are not aware of published research on the topic. Larger parties may tolerate longer waits because they find it more difficult to move to another restaurant and because they know that it is hard for restaurants to accommodate them. To cover a broad range of competitive environments, the three factor levels used average wait tolerances of 15-30, 30-60, and 60-120 minutes for parties of 1 to 10, with equal differences between party sizes (e.g., for Level 1, party sizes of 1 to 10 had average wait tolerances of $15,16.5,18, \ldots, 28.5$, and 30 minutes, respectively).

\section{Special-Related Factors}

We used five special-related experimental factors, as summarized in Table 4. We based these factors loosely on the actual early-bird specials listed in Table S1 in the Online Appendix.

We describe the five factors subsequently.

Discount Level had three levels, representing discounts off the original average check by party size of 5\%, 10\%, and 30\%. Demand Bump, which had six levels, represents the increase in customer arrivals resulting from the early-bird or night-owl special. The first three levels were applied as a demand multiplier, while Levels 4 through 6 represented additive demand. For example, Level 1 represented an increase of $50 \%$, times the discount, times demand expected in each time period the special was offered; while Level 4 added 50\%, times the discount, times the full-capacity demand, to any period in which the special was offered. So, if the discount level was 10\%, a 50\% demand bump would 


\section{INSERT TABLE 4 HERE}

be an increase of $5 \%$ of the initial demand (1/410\% 50\%) for Level 1 and an increase of $5 \%$ of the full capacity demand for Level 4. Figure 1 in the online Appendix gives an example.

Special Window, which has three levels, defines the time window in which the special applies. It is applied similarly in both the early-bird and night-owl cases, with the difference being that the special window starts at the restaurant open in the early-bird case, while the window ends at restaurant close in the night-owl case. The lower the level of the special window factor, the earlier (later) the early-bird (night-owl) special ends (starts); that is, it ends (starts) further away from the peak demand period.

To illustrate how the Special Window is operationalized in the early-bird studies, consider the case where the ramp-up period is 2 hours (120 minutes). Recall that the mean dining duration in 60 minutes in all cases. The first level of the Special Window has the special ending at the start of the peak less two thirds of the mean dining duration, which means that the special applies from time zero (when the restaurant opens) through minute 80 (= $120-2 / 3$ x 60). The second level of the Special Window has the special ending at the start of the peak less one third of the mean dining duration, which means that the special applies from time zero through minute 100 (= 120-1/3 x 60). Finally, the third level of the Special Window has the special ending at the start of the peak, which means that the special applies from time zero through minute 120.

Special Application, which has two levels, determines how the special applies. This factor has two levels. Level 1 applies a special based on the time at which a party arrives, while Level 2 applies a special based on the time at which a party was seated. Obviously, in Level 2, some customers who arrive within the early-bird special window might not actually be able to get the special, if they had to wait for a table. 


\section{Simulation Process}

The combinations of environmental and special-related factors yielded a total of 15,696 scenarios in Studies 1, 2, 5, and 6 and 7,920 scenarios in Studies 3, 4, 7, and 8. The scenarios arise from the 144 combinations of environmental conditions, times 109 (55) combinations of special conditions (including the no special, base case) for Studies 1, 2, 5, and 6 (3, 4, 7, and 8).

We conducted the simulations studies, which had an embedded optimization process, using a built-from-scratch restaurant simulator, similar to the TableMix model described by Thompson (2002). For each scenario in each study, we used a search process to identify the revenue maximizing mix of tables. We did this to ensure that the table mix was the most appropriate possible for the given restaurant scenario, which, we believe, helps ensure that any inaccuracy of the special value estimators is a function of the estimators themselves, rather than because we used a nonrevenue-maximizing table mix. The optimization search process we used was similar to that described by Kimes and Thompson (2005)— based on Simulated Annealing and using 100 iterations - who found their table-mix heuristic yielded solutions within $0.1 \%$ of optimal table mixes. Using an optimal process was impractical, given the size of our studies. For each scenario, we simulated 100 days of operation, which is the equivalent of a year's worth of peak meal-period operations (with two peak days a week, typically Friday and Saturday). As the key output from each scenario, we collected the actual revenue obtained using the best performing table mix. We then compared this revenue to that obtained when we simulated the comparable no special scenario, yielding a (simulated) net revenue from the special operative in the scenario. Finally, we compared the simulated net revenue to that estimated by each of the back-of-the-envelope calculations, that is, Equations 1-7. 


\section{Results}

To evaluate the three estimates of special value, we assume that managers use the following decision rule: If the estimated value of the special equals or exceeds a specified hurdle value, then implement the special. This decision rule yields two obvious performance metrics. The first is the Profitable Decision Percentage, which we measure as the percentage of scenarios in which an estimator predicts that the value of the special will equal or exceed a specified hurdle value, and the actual value achieved is positive:

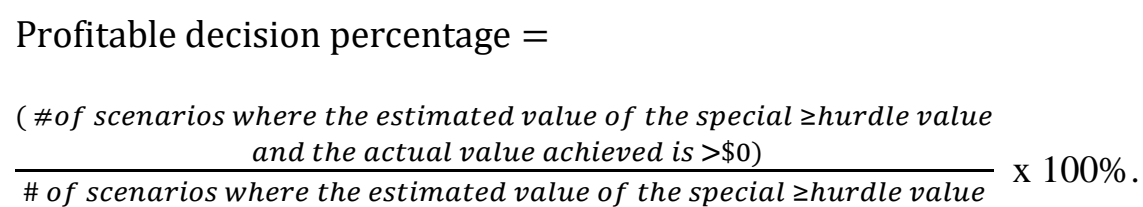

The estimated special value in Equation 8 comes from the back-of-the-envelope estimates, while the actual value comes from the simulated restaurant operations.

We use the metric defined in Equation 8 to explore the effects of different cannibalization adjustment factors and different hurdle values, for the early-bird (Figure 1a) and night-owl (Figure 1b) specials. Unsurprisingly, the Profitable Decision Percentage increases as the hurdle value increases, because the likelihood that a restaurant makes money from the special in practice increases with higher estimated values of the special. However, the percentage also increases as the cannibalization adjustment factor increases, indicating the importance of considering the cannibalization effect. For both specials, though, the increase in Profitable Decision Percentage generally plateaus (at lower cannibalization adjustment factor values for higher hurdle values). A comparison of the early-bird and night-owl cases shows that the Profitable Decision Percentage is higher across the board for the night-owl specials.

We next present a comparison between the Profitable Decision Percentage across estimation methods, which is illustrated in Figure 2. For this comparison, we fixed the cannibalization adjustment factor at 0.90 for ValEst3, which as Figure 1 shows, yielded a consistently high Profitable Decision 
Percentage. In both the early-bird and night-owl cases, ValEst3 dominated, though, again, the percentage was higher for night-owl decisions, indicating that the estimated values of the night-owl specials proved to be more accurate than those of the early-bird specials. The ordering of the methods is consistent with our expectations regarding the relative performance of the methods of estimating the value of the specials.

The Profitable Decision Percentage is a somewhat lax metric. For example, an estimated special value of US $\$ 100$ that actually only yielded US\$1 would still be reported as a profitable decision. Because of this, we also use our second and more important performance metric, Value Achieved Percentage.

Value Achieved Percentage is the percentage of the estimated value of the special that is actually achieved. It is found by averaging, across any scenario where the estimated value of the special equals or exceeds a specified hurdle value, the ratio of the actual value of the special divided by the estimated value of the special, converted to a percentage by multiplying by $100 \%$ :

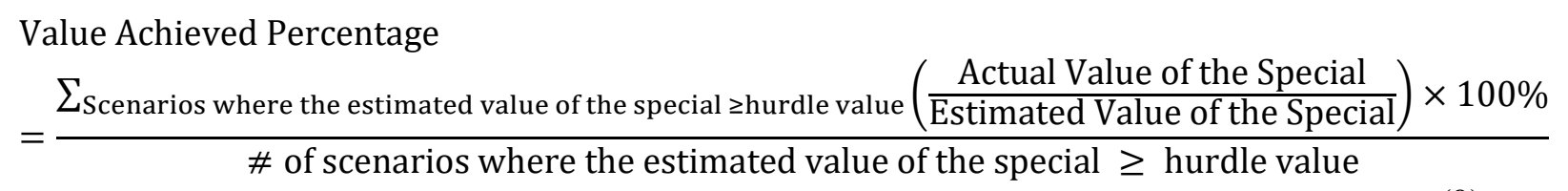

Again, we find the actual value of the special by simulating the restaurant operations and the estimated value of the special comes from ValEst1, ValEst2, and ValEst3. For managers to make the best decisions, Value Achieved Percentage should be 100\%, since that means the estimate of value was perfectly accurate; in other words, that the estimated benefits were fully achieved in practice.

Figure 3 shows the Value Achieved Percentage results for ValEst1 and ValEst2 and for ValEst3 using cannibalization adjustment factors ranging from 0.2 to 2.0, for the early-bird and night-owl studies. As the figure shows, the Value Achieved Percentage sometimes exceeded 100\%. This happens when the cannibalization adjustment factor over-predicts the amount of cannibalization that actually occurs. For the early-bird cases, higher values of the cannibalization adjustment factor tended to work better than lower values. However, as the hurdle value increased, the best Value Achieved Percentage dropped to just under $50 \%$-in other words, the actual revenue benefit from implementing the special was less than half what 
the best value estimator indicated it would be. Across all hurdle values, a cannibalization adjustment factor of 1.6 yielded the highest average Value Achieved Percentage for the early-bird studies, at 70.14\%. This compares very favorably to the average Value Achieved Percentage of $-0.02 \%$ for ValEst 1 and $1.64 \%$ for ValEst2 and supports our expectations regarding relative effectiveness of the methods of estimating the value of the specials.

INSERT FIGURE 2 HERE

Value Achieved Percentage results were notably higher in the night-owl studies than in the earlybird studies. Across the hurdle values, the best cannibalization adjustment factor for ValEst3 was 1.0, which averaged a Value Achieved Percentage of 99.51\%. Again, this is notably better than the average Value Achieved Percentage of 28.24\% for ValEst1 and 31.78\% for ValEst2 and supports our expectations.

Table 5 transforms the results illustrated in Figure 3 to evaluate the best overall cannibalization adjustment factor. It reports the Value Achieved Percentage, by special and by hurdle values, and compares the best hurdle value-specific cannibalization adjustment factor with the best overall cannibalization adjustment factor. There are notable differences in results across the specials. For the early-bird specials, the best overall cannibalization adjustment factor of 1.6 was the best for three of the five hurdle values and close to the best hurdle-specific cannibalization adjustment factor for the other two hurdle values. By contrast, for the night-owl specials, the best cannibalization adjustment factor increased as the hurdle value increased, from 0.6 with US\$10 and US\$25 hurdle values, to 1.2 with US\$100 and US\$200 hurdle values. The best overall cannibalization adjustment factor of 1.0 was the best only for the US\$50 hurdle value.

To explore the factors that could be affecting the accuracy of the ValEst3 estimate of the value of an early-bird special, we ran a regression analysis. The dependent variable was the actual value of the 
special (from the simulation), expressed as a percentage of the estimated special value from ValEst $_{e b}$ (i.e., the Value Achieved Percentage). We used a cannibalization adjustment factor of 1.6, since that yielded the best overall results as illustrated in Figure 3. The independent variables were the level indexes of the environmental and special-related factors. We imposed a restriction that the scenario needed to have an estimated value of the special that equaled or exceeded a US\$100 hurdle value, which was achieved in 3,144 of the 47,232 scenarios in Studies 1-4. Results of this regression are given in Table 6. All of the factors were statistically significant at the $\alpha=.001$ level, except for the length of the peak demand window, the demand bump/shift, and when the special applies, which were not significant at the $\alpha=.05$ level. The actual value achieved was a higher percentage of the estimated value for:

- the smaller restaurant (compared to the smaller restaurant, the larger restaurant decreased the Value Achieved Percentage by 15.3 percentage points);

- $\quad$ higher peak demand intensity (each increase in demand intensity increased the Value Achieved Percentage by 16.5 percentage points);

INSERT FIGURE 3 HERE

INSERT TABLE 5 HERE

INSERT TABLE 6 HERE

- longer ramp-up periods (compared to the 1-hour ramp-up, a 2-hour ramp-up increased the Value Achieved Percentage by 61.2 percentage points); 
- more similar dining durations across party sizes (compared to the lower duration variation, the higher variation decreased the Value Achieved Percentage by 5.5 percentage points);

- a longer waiting tolerance (each increase in wait tolerance increased the Value Achieved Percentage by 8.4 percentage points);

- higher levels of the discount (each increase in the discount increased the Value Achieved Percentage by 17.9 percentage points); and

- a longer special window (each increase in the length of the special window increased the Value Achieved Percentage by 28.7 percentage points).

We note that the scenarios in which the hurdle value is achieved are not equally distributed across the studies. Figure 4 illustrates the percentage of scenarios in each study where the hurdle value is achieved for ValEst3. We used the cannibalization adjustment factor values reported earlier that yielded the best Value Achieved Percentage results (i.e., a value of 1.6 for the early-bird studies and a value of 1.0 for the night-owl studies). Not shown are Studies 3 and 7, where no scenarios achieved the hurdle value. These results clearly demonstrate that the hurdle values are achieved much more often when demand increases in the special period than when it is shifted into the special period.

\section{Discussion and Conclusions}

\section{Contributions to Service Theory}

In this article, we examined a specific context of service capacity-demand management, specifically the use of early-bird and night-owl specials in restaurants to increase demand in the pre- and post-peak periods, respectively. Many researchers have advocated price discounts and specials to increase non-peak demand, beginning with Sasser (1976).

To investigate the use of early-bird and night-owl specials in restaurants, we developed three back-of-the-envelope estimates for the value of such specials. We found that estimating the value of the 
specials was most effective when the effect of cannibalization of full-fare business was included (i.e., ValEst3). Across our four early-bird (night-owl) studies, a cannibalization adjustment factor of 1.6 (1.0) proved to yield the best estimate of the value of the specials (i.e., a Value Achieved Percentage closest to 100\%). Nonetheless, the efficacy of back-of-the-envelope calculations for predicting the revenue increase from specials had mixed results_-performing quite well for night-owl specials, but notably less well for early-bird specials. While our simulation-based studies had a large number of assumptions, the nature of the assumptions was such that they are unlikely to have notably affected the accuracy of the calculations, with one exception, which we address subsequently. The results from four simulation-based studies showed that the revenue actually achieved for early-bird specials was at times under $50 \%$ of that estimated by the best of the back-of-the-envelope calculations (ValEst3, with a cannibalization adjustment factor of 1.6). Our results show that the back-of-the- envelope calculations of the revenue benefit of earlybird specials fall, like those of the benefits of reducing dining duration (Thompson 2011b), in the “seriously inaccurate”, category. However, the cannibalization-based value estimation was much better for the night-owl specials. We speculate that this is because these specials bring people into the restaurant after the peak period, when demand is tailing off, and so there is a more natural separation between the peak and post-peak period than between the pre-peak and peak periods.

\section{INSERT FIGURE 4 HERE}

The results show that how the early-bird specials affect overall revenue is more complex than just a simple cannibalization effect. The reason for this is that the best cannibalization adjustment factor was 1.6 for the early-bird studies, yet the net value achieved was only about $50 \%$ of that estimated under the highest hurdle value we examined, and about $70 \%$ across all the hurdle values. If it was simple to measure cannibalization, a higher cannibalization adjustment factor would have led to a higher revenue yield than 
what we observed. In reality, cannibalization is difficult to capture simply, perhaps because of the variation in dining duration both within and across party sizes.

Early-bird and night-owl specials are two of the processes that bridge marketing and operations. If marketing took a back-of-the-envelope approach to predicting the revenue benefits of the early-bird specials, operations might well be blamed when the revenue did not materialize as expected. This would be a classic case of marketing-operations conflict. The poor performance of the value estimators in the early-bird context supports Sasser's (1976) warning that operational results may not be as good as expected when attempting to increase business in slow periods. The poor performance conflicts with the Klassen and Rohleder's (2002) findings regarding the benefit of shifting demand in capacity constrained services. This discrepancy could be explained by their specific context, in that they did not consider how service spills over-from the pre-peak period to the peak period and from the peak period to the postpeak period—and so capacity cannibalization was not operative in their study.

\section{Managerial Implications}

We see at least five implications for practice from our findings. First and foremost, managers would need to be very cautious using back-of-the-envelope calculations for estimating the effectiveness of early-bird specials. While ValEst3 was the best predictor of special value, it was still far from fully accurate. Because of the lower captured revenue (i.e., at times less than $50 \%$ of that estimated), managers could well make incorrect decisions to implement the specials, thinking that the benefit they would get would be much higher than what they actually get, which seems consistent with Lefever’s (1989) criticism of the specials. Instead, managers' efforts to improve a restaurant's revenue perhaps would better be directed elsewhere. Alternatively, if a manager really is interested in implementing an early-bird special, the best advice would be to forgo a simple calculation and instead resort to a simulation of real restaurant operations to see how the special might play out. To that end, Evangelist et al. (2002) demonstrates the benefits of using a complex simulation model in service capacity-demand context. Should simulation be impractical, it would be safest to use a cannibalization adjustment factor of 1.6, 
since that value performed well across all hurdle values. While full or close-to-full revenue benefits can be expected at hurdle values of US\$25 or under, it would be appropriate to assume that only half the expected benefit would be achieved when hurdle values were US\$100 or higher.

Second, managers should be reasonably confident in using the back-of-the-envelope calculations for estimating the effectiveness of night-owl specials, with a couple of provisos. First, the proportion of customers who will use the special must be estimated accurately. Second, it is important to consider the cannibalization effects (using ValEst3), and we found that using a cannibalization adjustment factor of 1.0 worked best overall for night-owl specials. We note, however, that the best cannibalization adjustment factor was very dependent on the hurdle value, with the best cannibalization adjustment factor increasing under higher hurdle values.

Third, while we assumed that the dining duration would be the same for those patrons selecting the special, a lower duration would reduce the cannibalization effect in the early-bird case. A reduced duration would improve the viability of specials and improve the accuracy of the back-of-the-envelope calculations. So, a restaurateur would want to ensure the early-bird parties could be served quickly and have the tables ready as quickly as possible. A lower duration could be achieved through offering a more limited menu, consistent with Klassen and Rohleder’s (2001) suggestion of service differentials.

Fourth, our regression results yield insight into situations where early-bird specials are likely to be most effective: those where demand ramps up more slowly, over a longer time, to reach its peak and when a restaurant's demand was well above capacity. The former contributes to a separation between the special period and the peak period, thus reducing the complex effects of cannibalization, while in the latter case, the excess demand may be better captured using the special.

Fifth, we made an assumption in the studies that level of demand increase (or demand shift) used in the back-of-the-envelope calculations would actually be achieved. In reality, this is uncertain, and so the actual revenues may well be even lower than what we saw in our simulation results. 


\section{Limitations and Future Research}

While the poor performance of even the best value estimator in the case of early-bird specials would seem to warrant the development of better estimates of the value of those specials, we do not view this as a particularly useful endeavor. First, as we noted previously, it would likely require a more sophisticated method than just a simple estimate of the cannibalization effect. Second, a more direct and accurate approach is to use a sufficiently complex simulation model.

While we found that the value of night-owl specials can be estimated with reasonable accuracy, an unresolved issue is whether demand can be time-shifted into the post-peak period. The paucity of real examples of night-owl specials suggests it is difficult, but studies may help determine whether this is the case.

As noted earlier, a lowered dining duration in the special period should improve the accuracy of the estimates and their overall benefit. While this suggests that offering a more limited menu might be more effective than simply offering a discount on the regular menu, we leave this investigation to future research.

We observed that the specials were more effective when demand increased in the nonpeak period, rather than when it was shifted. However, this may be a result of the demand intensity values we used, since the greater the amount by which demand exceeds capacity, the more benefit that would be expected by time shifting the excess. It would be interesting to examine the effects of time-shifting demand or raising prices in the peak periods, under higher levels of excess demand than what we considered.

Finally, while our study assumed all parties were walk-ins, an effective reservation system could help limit the extent to which the early-bird or night-owl customers affect the capacity used for full-fare customers. We leave this issue for future research.

In closing, we note that our findings offer further support for the need to think holistically about marketing and operations, as espoused by Kwortnik and Thompson (2009). The difference between the accuracy of revenue estimates for early-bird and night-owl specials shows that context - that is, when a special is offered-really matters. 


\section{References}

Anonymous (2014), 2014 Restaurant Industry Pocket Factbook. Washington, DC: National Restaurant Association.

Bell, Rick and Patricia L. Pliner (2003), “Time to Eat: The Relationship between the Number of People Eating and Meal Duration in Three Lunch Settings,’’ Appetite, 41, 215-218.

Crandall, Richard E. and Robert E. Markland (1996), “'Demand Management— Today’s Challenge for Service Industries,’’ Production and Operations Management, 5 (Summer), 106-120.

Dixon, Michael, Ekaterina V. Karniouchina, Bo van der Rhee, Rohit Verma, and Liana Victorino (2014),

“The Role of Coordinated Marketing-Operations Strategy in Services: Implications for

Managerial Decisions and Execution,’’ Journal of Service Management, 25 (2), 275-294.

Evangelist, Shane, Badger Godwin, Joey Johnson, Vincent Conzola, Robert Kizer, Stephanie YoungHelou, and Richard Metters (2002), “'Linking Marketing and Operations: An Application at Blockbuster, Inc.,’ Journal of Service Research, 5 (November), 91-100.

Field, Arthur, Mark McKnew, and Peter Kiessler (1997), “'A Simulation Comparison of Buffet Restaurants: Applying Monte Carlo Modeling,'’ Cornell Hotel and Restaurant Administration Quarterly, 38 (December), 68-79.

Kimes, Sheryl E., Richard B. Chase, Sunmee Choi, Philip Y. Lee, and Elizabeth N. Ngonzi (1998), “'Restaurant Revenue Management: Applying Yield Management to the Restaurant Industry,” Cornell Hotel and Restaurant Administration Quarterly, 39 (June), 32-39.

Kimes, Sheryl E. and Jonathan Beard (2013), “'The Future of Restaurant Revenue Management,’” Journal of Revenue and Pricing Management, 12 (September), 464-469.

Kimes, Sheryl E. and Stephani K. A. Robson (2004), “The Impact of Restaurant Table Characteristics on Meal Duration and Spending,’' Cornell Hotel and Restaurant Administration Quarterly, 45 (November), 333-346.

Kimes, Sheryl E. and Gary M. Thompson (2004), “'Restaurant Revenue Management at Chevys: Determining the Best Table Mix,’’ Decision Sciences, 35 (Summer), 371-391. 
Kimes, Sheryl E. and Gary M. Thompson (2005), “An Evaluation of Heuristic Methods for Determining the Best Table Mix in Full-Service Restaurants,'” Journal of Operations Management, 23 (February), 197-208.

Klassen, Kenneth J. and Thomas R. Rohleder (2001), “Combining Operations and Marketing to Manage Capacity and Demand in Services,’’ The Service Industries Journal, 21 (April), 1-30.

Klassen, Kenneth J. and Thomas R. Rohleder (2002), “Demand and Capacity Management Decisions in Services: How they Impact on One Another,’' International Journal of Operations and Production Management, 22 (5), 527-548.

Kumar, V., Katherine N. Lemon, and A. Parasuraman (2006), “'Managing Customers for Value: An Overview and Research Agenda,’’ Journal of Service Research, 9 (November), 87-94.

Kwortnik, Robert J. Jr. and Gary M. Thompson (2009), “Bridging Services Marketing and Operations: A Call for Service Experience Management,’’ Journal of Service Research, 11 (May), 389-406.

Lefever, Michael M. (1989), “'Restaurant Advertising: Coupons, Clowns, and Cadillacs,’’ Cornell Hotel and Restaurant Administration Quarterly, 29 (February), 92-101.

Lovelock, Christopher H. (1984), “'Strategies for Managing Demand in Capacity-Constrained Service Organisations,”' The Service Industries Journal, 4 (November), 12-30.

Ostrom, Amy L., Mary Jo Bitner, Stephen W. Brown, Kevin A. Burkhard, Michael Goul, Vicki SmithDaniels, Haluk Demirkan, and Elliot Rabinovich (2010), “'Moving Forward and Making a Difference: Research Priorities for the Science of Service,’ Journal of Service Research, 13 (February), 4-36.

Quain, Bill, Michael W. Sansbury, and Stephen M. LeBruto (1999), “'Revenue Enhancement, Part 4: Increasing Restaurant Profitability,', Cornell Hotel and Restaurant Administration Quarterly, 40 (June), 38-47.

Pullman, Madeleine E. and Gary M. Thompson (2003), “'Strategies for Integrating Capacity with Demand in Service Networks,’’ Journal of Service Research, 5 (February), 169-183. 
Rhyne, David M. (1988), “'The Impact of Demand Management on Service System Performance,’ The Service Industries Journal, 8 (October), 446-458.

Sasser, W. Earl (1976), “Match Supply and Demand in Service Industries,’’ Harvard Business Review, 54 (November-December), 133-140.

Susskind, Alex M., Dennis Reynolds, and Eriko Tsuchiya (2004), “'An Evaluation of Guests’ Preferred Incentives to Shift Time-Variable Demand in Restaurants,'” Cornell Hotel and Restaurant Administration Quarterly, 45 (February), 68-84.

Thompson, Gary M. (2002), “'Optimizing a Restaurant’s Seating Capacity: Use Dedicated or Combinable tables?’’ Cornell Hotel and Restaurant Administration Quarterly, 43 (August), 48-57.

Thompson, Gary M. (2009), “(Mythical) Revenue Benefits of Reducing Dining Duration in Restaurants, ”Cornell Hotel and Restaurant Administration Quarterly, 50 (February), 96-112.

Thompson, Gary M. (2010), “'Restaurant Profitability Management: the Evolution of Restaurant Revenue Management,'’ Cornell Hotel and Restaurant Administration Quarterly, 51 (August), 308-322.

Thompson, Gary M. (2011a), “Cherry-picking Customers by Party Size in Restaurants,’’ Journal of Service Research, 14 (May), 210-213.

Thompson, Gary M. (2011b), “Inaccuracy of the “Naive Table Mix”’ Calculations,”' Cornell Hotel and Restaurant Administration Quarterly, 52 (August), 241-252.

Thompson, Gary M. and Heeju J. Sohn (2009), “Time- and Capacity-based Measurement of Restaurant Revenue,’’ Cornell Hospitality Quarterly, 50 (November), 520-539.

Verma, Rohit, Gary M. Thompson, and Jordan J. Louviere (1999), “Configuring Service Operations in Accordance with Customers’ Needs and Preferences,’’ Journal of Service Research, 1 (February), 262-274.

Wirtz, Jochen and Sheryl E. Kimes (2007), “The Moderating Role of Familiarity in Fairness Perceptions of revenue Management Pricing,’’ Journal of Service Research, 9 (February), 229-240. 
Table I. The Structure of the Eight Simulation Studies.

\begin{tabular}{llll}
\hline & & Demand Increase & \\
Study & Type of Special & or Shift & Who Gets the Special \\
\hline I & Early Bird & Increase & All parties \\
2 & Early Bird & Increase & Only incremental parties \\
3 & Early Bird & Shift earlier & All parties \\
4 & Early Bird & Shift earlier & Only the shifted parties \\
5 & Night Owl & Increase & All parties \\
6 & Night Owl & Increase & Only incremental parties \\
7 & Night Owl & Shift later & All parties \\
8 & Night Owl & Shift later & Only the shifted parties \\
\hline
\end{tabular}


Table 2. Environmental Experimental Factors.

\begin{tabular}{|c|c|}
\hline $\begin{array}{l}\text { Environmental } \\
\text { Factor }\end{array}$ & \# Levels: Levels \\
\hline Restaurant size & 2: 50 and 200 seats \\
\hline $\begin{array}{l}\text { Peak demand } \\
\text { intensity }\end{array}$ & 3: $90 \%, 100 \%$, and $110 \%$ of "full capacity" \\
\hline $\begin{array}{l}\text { Length of peak } \\
\text { period }\end{array}$ & 2: 2 and 4 hours \\
\hline $\begin{array}{l}\text { Length of ramp-up } \\
\text { period }\end{array}$ & $\begin{array}{l}\text { 2: I and } 2 \text { hours for Studies I-4 } \\
\text { I: I hour for Studies } 5-8\end{array}$ \\
\hline $\begin{array}{l}\text { Length of ramp- } \\
\text { down period }\end{array}$ & $\begin{array}{l}\text { I: I hour for Studies I-4 } \\
\text { 2: I and } 2 \text { hours for Studies } 5-8\end{array}$ \\
\hline $\begin{array}{l}\text { Dining duration by } \\
\text { party sizes }\end{array}$ & $\begin{array}{l}\text { 2: } 1.5 \text { and } 2.0 \text { for the ratio of dining time for a } \\
\text { party of } 10 \text { to the dining time for a party of } 1\end{array}$ \\
\hline $\begin{array}{l}\text { Wait tolerance by } \\
\text { party size }\end{array}$ & $\begin{array}{l}\text { 3: Average wait tolerance of } 15-30,30-60 \text {, and } \\
60-120 \text { minutes for parties of } 1 \text { to } 10\end{array}$ \\
\hline
\end{tabular}


Table 3. Party Size Probabilities and Mean Dining Durations.

\begin{tabular}{|c|c|c|c|c|c|c|c|c|c|c|}
\hline Party Size & I & 2 & 3 & 4 & 5 & 6 & 7 & 8 & 9 & 10 \\
\hline Probability & .28 & .40 & .13 & .07 & .03 & .02 & .02 & .02 & .02 & .01 \\
\hline Mean duration (low variation across party sizes) & 55.10 & 58.16 & 61.22 & 64.29 & 67.35 & 70.41 & 73.47 & 76.53 & 79.59 & 82.65 \\
\hline Mean duration (high variation across party sizes) & 50.94 & 56.60 & 62.26 & 67.92 & 73.58 & 79.25 & 84.91 & 90.57 & 96.23 & 101.89 \\
\hline
\end{tabular}


Table 4. Special-Related Experimental Factors.

\begin{tabular}{|c|c|c|}
\hline $\begin{array}{l}\text { Special-Related } \\
\text { Factor }\end{array}$ & \# Levels: Levels & $\begin{array}{l}\text { Applies in } \\
\text { Studies }\end{array}$ \\
\hline Discount Level & 3: $5 \%, 10 \%$, and $30 \%$ off initial price & $\mathrm{I}-8$ \\
\hline Demand bump & $\begin{array}{l}\text { 6: Levels I-3 additional demand of } 50 \%, 100 \% \text {, and } 150 \% \text { of the discount level, times initial demand (by time } \\
\text { period); Levels } 4-6 \text { additional demand of } 50 \%, 100 \% \text { and } 150 \% \text { of the discount level, times "full capacity" } \\
\text { demand }\end{array}$ & $1-2,5-6$ \\
\hline Demand shift & $\begin{array}{l}\text { 3: Shifting of } 50 \%, 100 \% \text {, and } 150 \% \text { of the discount level times existing demand (by time period) in the peak } \\
\text { period one hour earlier (Studies 3-4) or later (Studies 7-8) into the discount window }\end{array}$ & $3-4,7-8$ \\
\hline \multirow[t]{2}{*}{ Special window } & $\begin{array}{l}\text { 3: Applies from restaurant opening until start of peak demand minus } x \text { of mean dining duration, where } x \text { is } 2 / \\
3,1 / 3 \text {, and } 0\end{array}$ & $1-4$ \\
\hline & $\begin{array}{l}\text { 3: Applies from the end of the peak demand plus } x \text { of mean dining duration (where } x \text { is } 2 / 3,1 / 3 \text {, and } 0 \text { ), until } \\
\text { restaurant close }\end{array}$ & $5-8$ \\
\hline Special application & 2: When a party arrives and when a party is seated & $1-8$ \\
\hline
\end{tabular}



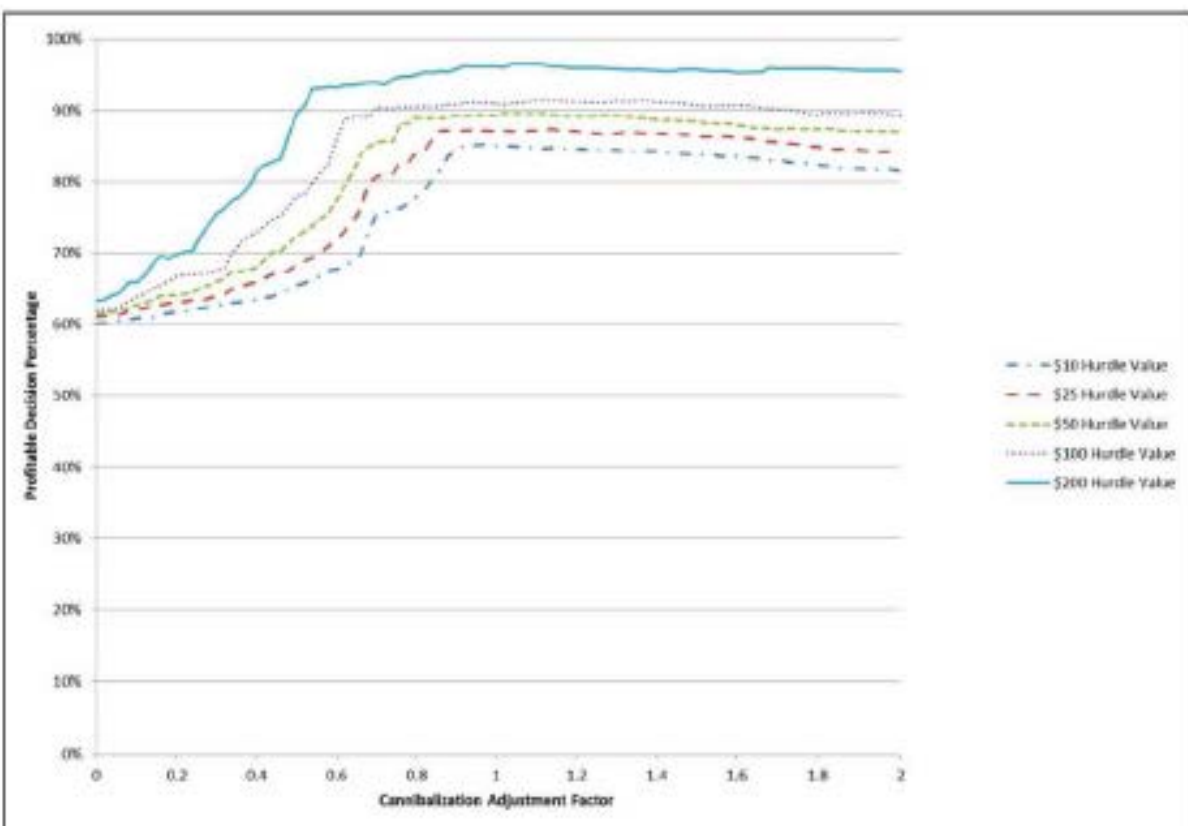

a) Early-Bird specials (Studies 1-4)

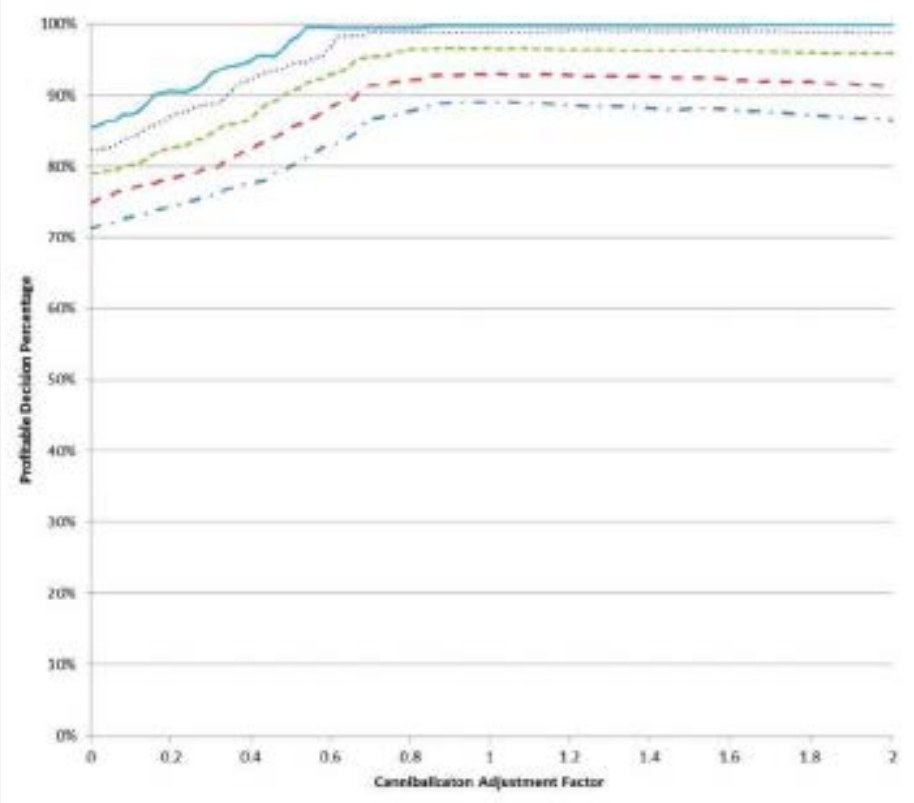

- - - s10urde vaue - - soshardo valus c..... S50 Harde vaue

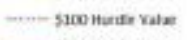
- 5000 Harde valo

\section{b) Night-Owl specials (Studies 5-8)}

Figure I. Profitable decision percentage as a function of the cannibalization adjustment factor. 


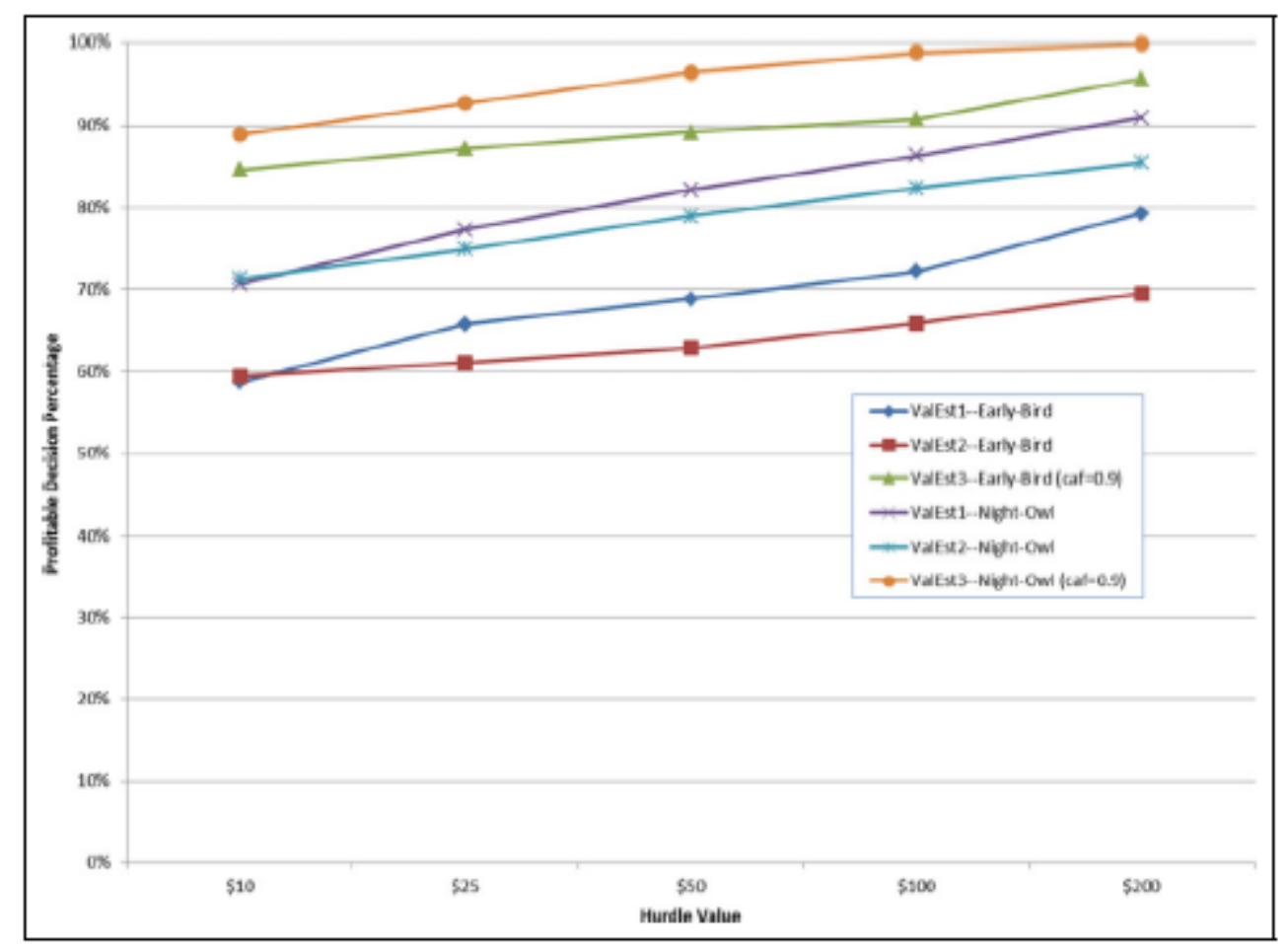

Figure 2. Profitable decision percentage by estimation method. 


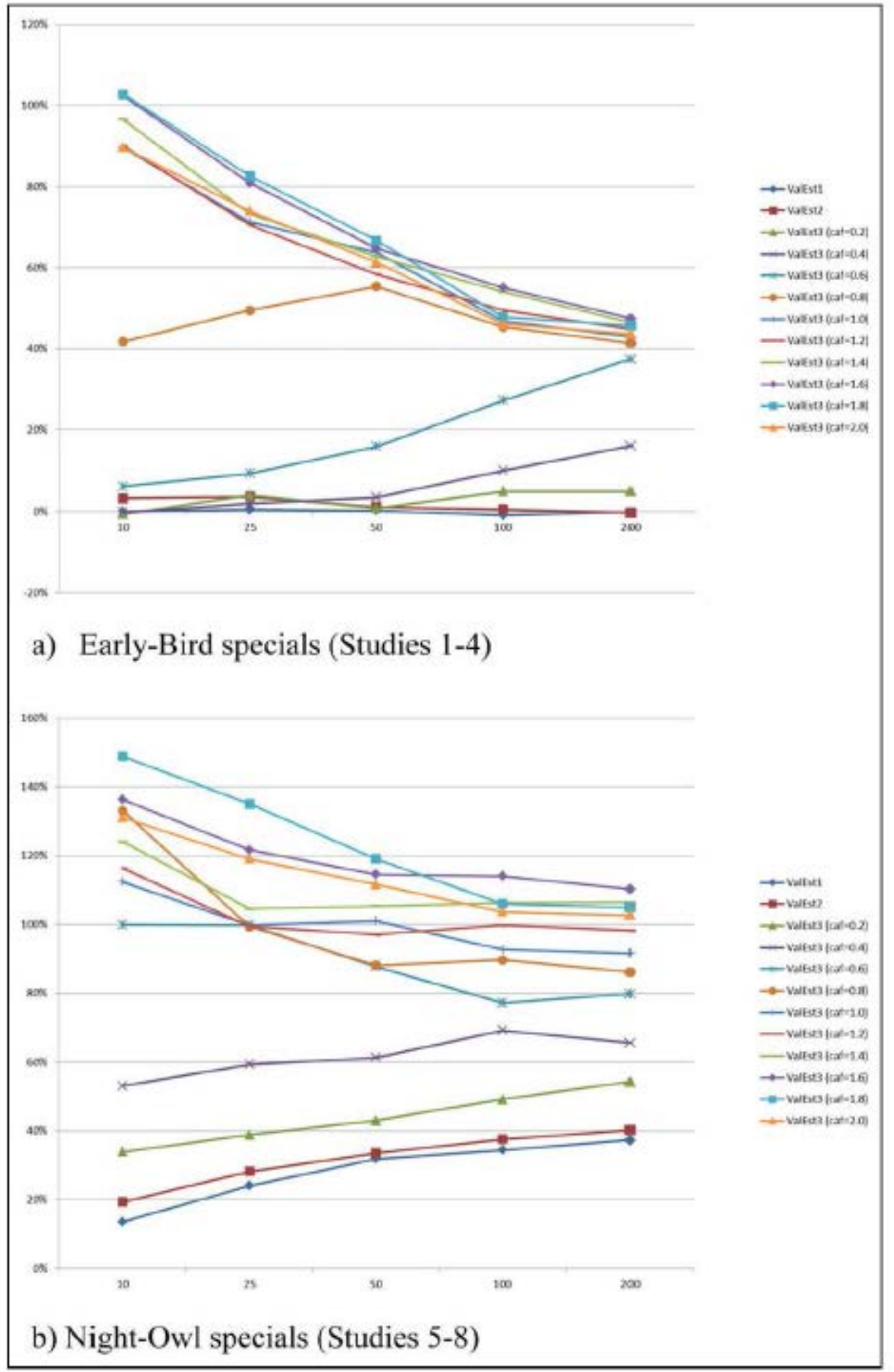

Figure 3. Value Achieved Percentoge, by hurdle value, for ValEstl, ValEst2, and VaEst3 (under different cannibalization adjustment factors). 
Table 5. Value Achieved Percentage, by Special and Hurdle Values, for the Best Hurdle-Specific Cannibalization Adjustment Factor and the Best Overall Cannibalization Adjustment Factor.

\begin{tabular}{lcccccc}
\hline Special (Studies) & CAF $^{\mathrm{a}}$ & US\$10 Hurdle & US\$25 Hurdle & US\$50 Hurdle & US\$100 Hurdle & US\$200 Hurdle \\
\hline Early Bird (I-4) & Best $^{\mathrm{b}}$ & $102.4 \%(1.6)$ & $82.6 \%(1.8)$ & $66.7 \%(1.8)$ & $55.1 \%(1.6)$ & $47.5 \%(1.6)$ \\
& $1.6^{\mathrm{c}}$ & $102.4 \%$ & $80.9 \%$ & $64.7 \%$ & $55.1 \%$ & $47.5 \%$ \\
Night Owl (5-8) & Best $^{\mathrm{b}}$ & $99.9 \%(0.6)$ & $99.8 \%(0.6)$ & $101.0 \%(1.0)$ & $99.7 \%(1.2)$ & $98.2 \%(1.2)$ \\
& $1.0^{\mathrm{d}}$ & $112.3 \%$ & 99.8 & $101.0 \%$ & $92.7 \%$ & $91.7 \%$ \\
\hline
\end{tabular}

${ }^{a} \mathrm{CAF}=$ cannibalization adjustment factor. ${ }^{\mathrm{b}}$ Best $=$ Value Achieved Percentage for the best hurdle-special cannibalization adjustment factor (and the best cannibalization adjustment factor for the specific hurdle value). ${ }^{\mathrm{C} O}$ verall best cannibalization adjustment factor for the early-bird studies. ${ }^{\mathrm{d}}$ Overall best cannibalization adjustment factor for the night-owl studies. 
Table 6. Results of Regression Predicting Value Achieved Percentage.

\begin{tabular}{|c|c|}
\hline$N$ & 3,144 \\
\hline Mean value of dependent variable & 55.12 \\
\hline$R^{2}$ & .404895 \\
\hline Adjusted $R^{2}$ & .402995 \\
\hline Standard error & 42.3625 \\
\hline \multicolumn{2}{|l|}{ Variables and coefficients } \\
\hline Intercept & $-165.302^{* * *}$ \\
\hline Restaurant size & $-15.2868^{* * 1 \%}$ \\
\hline Peak demand intensity & $16.46516^{* * 1 \% *}$ \\
\hline Length of the peak period ( 2 hours, 4 hours) & 2.575308 \\
\hline Length of the ramp-up period (I hours, 2 hours) & $61.24943^{* 1 \%}$ \\
\hline Dining duration variation by party sizes $(1.5,2.0)$ & $-5.45704^{* 10 *}$ \\
\hline Wait tolerance by party size $(15,30$, and 60 minutes $)$ & $8.35478^{*}$ \\
\hline Discount level $(0.95,0.9$, and 0.7$)$ & $17.92388^{\text {*16k }}$ \\
\hline Demand bump/shift $(0,0.1,0.2$, and 0.4$)$ & 0.342604 \\
\hline Special window $(2 / 3,1 / 3$, and 0$)$ & $28.7450 \%$ \% \\
\hline Special application $(1=$ arrival, $2=$ seated $)$ & 0.951748 \\
\hline
\end{tabular}

****Significant at $\alpha<.00 \mathrm{I}$. 


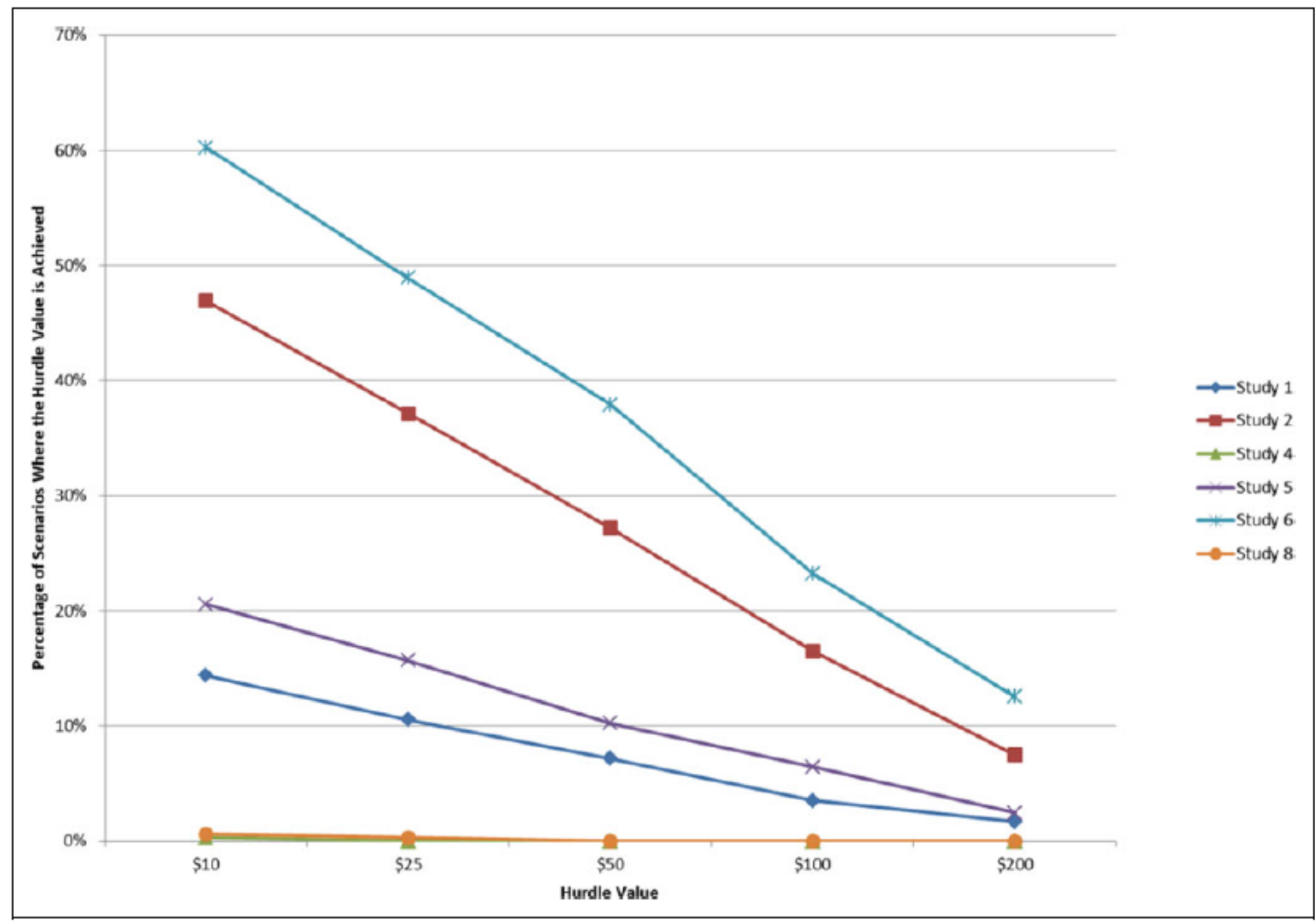

Figure 4. Percentage of scenarios, by study, where the ValEst3 achieves the specified hurdle value. 